\title{
Cursos de graduação da Escola de Ciência da Informação da Universidade Federal de Minas Gerais: propostas de expansão e flexibilização
}

Beatriz Valadares Cendón

Professora Doutora da Escola de Ciência da Informação da UFMG

Carlos Alberto Ávila Araújo

Professor Doutor da Escola de Ciência da Informação da UFMG

Cíntia de Azevedo Lourenço

Professora Doutora Escola de Ciência da Informação da UFMG

Lidia Alvarenga Professora

Doutora Escola de Ciência da Informação da UFMG

Lígia Maria Moreira Dumont

Professora Doutora Escola de Ciência da Informação da UFMG

Marlene de Oliveira

Professora Doutora Escola de Ciência da Informação da UFMG

Mônica Erichsen Nassif

Professora Doutora Escola de Ciência da Informação da UFMG

Renato Rocha Souza

Professor Doutor Escola de Ciência da Informação da UFMG 
Apresenta a nova proposta para os cursos de graduação em Biblioteconomia e Gestão da Informação, Arquivologia e Museologia da Escola de Ciência da Informação da UFMG. Propõe-se um tronco comum de atividades acadêmicas da área de ciência da informação para os três cursos, acrescidas pelas atividades obrigatórias, optativas e complementares livres. A intenção é que os alunos das três formações cursem o tronco comum em turmas mescladas e que as atividades específicas já se iniciem no segundo período, para que o aluno tenha clareza das especificidades do curso e da profissão por ele escolhidos. Os cursos prevêem articulação com outros cursos da Universidade Federal de Minas Gerais, garantindo assim a interdisciplinaridade e flexibilização curricular. $O$ aluno torna-se co-autor na montagem da sua grade curricular e conseqüentemente da sua formação.

Palavras-chave: Biblioteconomia - ensino; Arquivologia ensino; Museologia - ensino; Ciência da informação flexibilização curricular; Escola de Ciência da Informação da UFMG

\section{Introdução: marco referencial}

Os cursos de graduação da Escola de Ciência da Informação da UFMG - ECI foram re-estruturados e construídos em 2008 no bojo de um projeto pedagógico que abriga os novos cursos de Arquivologia e de Museologia, além da reestruturação curricular do Curso de Biblioteconomia já existente, que passa a se chamar Biblioteconomia e Gestão da Informação. A proposta final, aprovada por todo o corpo docente e posteriormente pela Congregação da Escola, foi a de criação de um tronco comum de atividades acadêmicas para os três cursos.

Os projetos pedagógicos hoje já definidos, ou seja, o do Curso de Biblioteconomia e Gestão da Informação e o do curso de Arquivologia, apresentam o conjunto de diretrizes e estratégias que visam fundamentar a prática pedagógica dos cursos $^{1}$.

As propostas pedagógicas dos cursos foram constituídas considerando-se os pontos compartilhados pelas três vertentes da ciência da informação, o que permitiu a criação de um tronco comum de 17 atividades acadêmicas a serem cursadas como obrigatórias em todos os

1 O projeto pedagógico do curso de Museologia será estruturado no segundo semestre do presente ano. 
três cursos. Para todos os perfis prevêem-se atividades acadêmicas também obrigatórias específicas para cada curso - onde inclui-se o estágio curricular -, atividades acadêmicas optativas, formação complementar e livre e outras atividades geradoras de crédito, que devem ser avaliadas pontualmente pelos colegiados dos cursos (ver grades curriculares em anexo).

A inclusão do termo "gestão da informação" no nome do Curso de Biblioteconomia, com a nova designação "Biblioteconomia e Gestão da Informação" visa primeiramente alinhar o currículo proposto com a denominação da Escola, que passou a chamar-se Ciência da Informação em 2000, adequando-se dessa forma às tendências mundiais. A escolha marca a opção pela diversificação da formação do aluno para atuar nas atividades de informação em bibliotecas e outros contextos.

A essência dessa decisão está diretamente relacionada com a forma como a ECI entende o que vem a ser a ciência da informação, a biblioteconomia, a arquivologia e a museologia. Esse entendimento vem se consolidando ao longo dos últimos anos, tendo como principais marcos as mudanças nos nomes do periódico científico editado na Escola - de Revista da Escola de Biblioteconomia da UFMG para Perspectivas em Ciência da Informação - e do programa de pós-graduação sediado na Escola - de Mestrado em Biblioteconomia para Programa de PósGraduação em Ciência da Informação - , ambos na metade da década de 1990. A mudança de nome da Escola para Escola de Ciência da Informação, em 2000, mostra também a busca da adequação à tendência verificada em nível mundial na área de ciência da informação e nas escolas de biblioteconomia de contemplar mudanças ocorridas no âmbito da própria escola, em termos da competência instalada, das agendas de pesquisa e das atividades desenvolvidas.

Naquele momento, reuniu-se na Escola uma comissão para a realização de um estudo que fundamentasse a proposta de mudança do nome da unidade e apontou-se como um dos pontos cruciais do projeto o interesse da escola em oferecer, posteriormente, os cursos de Arquivologia e Museologia (BARBOSA et al., 2000), consolidando a vocação da escola como um centro de ensino, pesquisa e extensão em todas as vertentes da ciência da informação. É por esse motivo que a proposta de reformulação curricular do Curso de Biblioteconomia (e de criação dos outros dois cursos de graduação) só pode ser pensada nesse processo de gradativo avanço na compreensão do relacionamento destas áreas com a ciência da informação.

O que se tem por proposta neste momento é o oferecimento de cursos que façam parte de um projeto mais amplo da área de ciência da informação - que se reflete, como se verá adiante, nas disciplinas e atividades do tronco comum - com todos os impactos epistemológicos e pedagógicos.

A crescente produção de conhecimentos científicos e tecnológicos, assim como o uso das novas tecnologias nas várias esferas sociais, implicou a transformação de algumas profissões. A profissão de 
bibliotecário foi uma dessas, impactada por diversas variáveis, não só pelo componente tecnológico, mas também por mudanças nos cenários econômico, social e cultural ocorridos com a globalização. Tais fenômenos registrados nas últimas décadas ocasionaram novos e diferentes contextos de informação, tornando premente não apenas a formação de maior número de bibliotecários, mas também de profissionais consoantes com seu tempo, sintonizados com os novos contextos de informação e as novas tecnologias que possam colaborar nas suas atividades cotidianas.

Alguns pesquisadores têm caracterizado o momento contemporâneo - denominado Sociedade da Informação - como uma nova etapa do desenvolvimento da sociedade por trazer em seu bojo grandes massas de conhecimentos e tecnologias adequadas para armazenar e organizar informações. A profissão de bibliotecário vem sendo repensada na tentativa de atender a novas demandas e novos procedimentos de organização e recuperação de informações. Isso implica no aprendizado de novas metodologias para organização, recuperação e uso da informação, não só nos contextos tradicionais, mas também nos diferentes tipos de bibliotecas e centros de informação que surgiram na sociedade contemporânea. Essas novas instituições que necessitam de acervos e informações organizados localizam-se em áreas industriais, comerciais, jurídicas, da saúde, financeira, governamental e de ciência e tecnologia.

Já o Curso de Arquivologia vem atender a interesses e expectativas sociais e administrativas, relativas à formação de profissionais para atuar nas áreas de gestão de documentos arquivísticos, em empresas e organizações, nas esferas pública e privada e nas instâncias da indústria, comércio ou terceiro setor. Atualmente, sabe-se que as atividades arquivísticas no Estado de Minas Gerais são quase sempre desempenhadas de forma precária, por profissionais sem formação específica. Não existe no Estado outro curso de arquivologia em nível de graduação.

Nas discussões sobre a carência da gestão documental na administração pública e a importância desse curso para o estado e país, tem sido destacado ainda o fato de que os documentos administrativos que formam a memória institucional, com o passar do tempo, constituemse em insumos valiosos para a história nacional que deve ser preservada e transmitida às gerações futuras.

\section{Referencias epistemológicas que fundamentam a criação dos cursos de Biblioteconomia e Gestão da Informação e de Arquivologia}

Ao longo do processo, todo o corpo docente da Escola reuniu-se diversas vezes para discutir e validar as sugestões apresentadas. Para iniciar as discussões e reflexões que antecedem um projeto dessa envergadura foi criada a Comissão Central de Reestruturação, constituída 
por dez professores. Os trabalhos da Comissão Central foram suplementados pelas seguintes sub-comissões temáticas:

- Fundamentos teóricos e metodológicos da ciência da informação;

- Princípios gerais da organização e tratamento da informação;

- Usuários de informação;

- Fundamentos culturais, políticos e sociais da informação;

- Gestão da informação;

- Fontes e uso de informação;

- Tecnologia da informação.

Posteriormente, foi criada uma comissão especialmente para o Curso de Arquivologia, a ser implementado em 2009. Será constituída ainda este ano a comissão de planejamento do Curso de Museologia, a ser implantado em 2010.

Embora gestada no período pós II Guerra Mundial, a ciência da informação como disciplina científica foi formalizada apenas na década de 50. Sua primeira conceituação surge na década de 60 , sendo uma das mais aceitas, aquela proposta por Borko (1968, p. 3) que definiu a área...

[...] como uma disciplina que investiga as propriedades e o comportamento da informação, as forças que governam seu fluxo e os meios de processamento para otimizar sua acessibilidade e utilização. Relaciona-se com o corpo de conhecimentos relativo à produção, coleta, organização, armazenagem, recuperação, interpretação, transmissão, transformação e utilização da informação.

As idéias de Borko apontam a essência do problema que orienta o campo da ciência da informação, que é o de organizar e disponibilizar para uso as informações sobre o que é culturalmente produzido. A evolução da área foi objeto de preocupação de Saracevic (1996, p. 47), que a redefiniu como...

[...] um campo dedicado a questões científicas e a prática profissional, voltadas para os problemas da efetiva comunicação do conhecimento e de registros do conhecimento entre seres humanos, no contexto social, institucional ou individual do uso e das necessidades de informação. No tratamento dessas questões são consideradas de particular interesse as vantagens das modernas tecnologias informacionais.

Conforme alguns autores, a ciência da informação surgiu com base no movimento documentalista e nos desenvolvimentos teóricos e tecnológicos que visavam uma melhor recuperação da informação. Foi muito importante na busca de sua identidade a Teoria Matemática da Informação. Para a ciência da informação, aquela teoria trouxe a necessidade de reconhecimento do seu objeto, a informação. O estudo do fenômeno informação transformou o ambiente da biblioteca que até então 
tinha como objeto o livro, a revista ou outros documentos em geral impressos. Visto pelo prisma da informação, um acervo de mil livros transforma-se em milhões de informações.

A biblioteconomia e a ciência da informação, conforme MIKSA (1992), têm paradigmas diferentes. O paradigma da primeira, segundo o autor, consiste em um grupo de idéias relacionadas com a biblioteca, então considerada como uma instituição social. Suas origens encontramse nos trabalhos dos estudiosos da Escola de Biblioteconomia de Chicago, durante os anos de 1920 a 1930. O ponto focal desse paradigma é a biblioteca em si mesma. E como organização social, a biblioteca tem material organizacional e características intelectuais que servem como significado para expressar suas funções em uma estrutura social. Porém, o que se tem verificado na seqüência dos anos é que a biblioteconomia passou a adotar teorias e metodologias da ciência da informação. As duas compartilham teorias e práticas principalmente de organização e recuperação de informação e de documentos em diferentes formas e temas. Tal postura de parceria entre as duas disciplinas deve-se a alguns fatos. Em primeiro lugar, as duas têm como meta a armazenagem, organização, recuperação e disseminação para uso os conhecimentos produzidos na sociedade. Em segundo lugar, a biblioteconomia passou a refletir e pesquisar suas temáticas de biblioteca no campo da ciência da informação. Dessa forma, mesmo como disciplinas diferentes, as duas partilham o mesmo objetivo, que é organizar e disponibilizar para uso o conhecimento produzido.

Segundo Saracevic (1996), a ciência da informação possui três características gerais: primeiro, é uma ciência interdisciplinar por natureza, estando a evolução desta interdisciplinaridade longe de terminar. Segundo, é uma ciência conectada diretamente à tecnologia da informação e terceiro, é uma ciência que participa ativamente na evolução da sociedade da informação.

Já a idéia de promover uma cooperação entre os trabalhos desenvolvidos por arquivos, bibliotecas e outros organismos de documentação surgiu em 1934 com Paul Otlet em sua obra Traité de documentation e mais tarde foi reforçada em um simpósio da UNESCO, 0 Simpósio Internacional para a Compatibilização da Formação Profissional e Treinamento em Ciência da Informação, Biblioteconomia e Arquivologia, realizado em outubro de 1984 . As discussões deram origem a um Plano de Ação que visava compatibilizar os cursos de formação profissional para essas áreas.

A literatura especializada mostra que por muito tempo foi manifestado um isolamento entre a biblioteconomia, a arquivologia e a museologia, com um grande ímpeto de defesa de espaços e competências, mas que na atualidade, o cenário científico acena para a busca da integração, tendo por alicerce o novo modelo da interdisciplinaridade e do compartilhamento.

Frente a esse panorama, a Escola de Ciência da Informação da UFMG propõe uma integralização desses três campos, onde a ciência da 
informação desenha a estrutura básica da formação desses profissionais da informação e oferece ramificações que possibilitem a formação especializada nos cursos de biblioteconomia, arquivologia e museologia.

Quanto à formação, em nível de mestrado e doutorado, cumpre ressaltar que o programa de Pós-Graduação em Ciência da Informação (PPGCI) da ECI já vem recebendo há algum tempo em suas linhas de pesquisa alunos que desejam se capacitar para a pesquisa nas áreas da arquivologia e da museologia e essa prática deverá ser intensificada, especialmente visando-se à formação de docentes para atuar nos cursos de graduação desses campos. Está prevista a incorporação das temáticas relativas a estas áreas nas atuais linhas de pesquisa existentes no PPGCI, podendo, ainda, haver articulação com outros programas da UFMG, tais como história, geociências, belas artes, ciências econômicas e ciência da computação, programas que já mantêm pesquisas e disciplinas com conteúdos de interesse para cursos de biblioteconomia, arquivologia e museologia. Docentes dessas unidades já discutem, com docentes da ECI, sobre essa possibilidade temática.

\section{Proposta de flexibilização curricular}

A estrutura geral dos novos cursos de graduação manterá sua duração atual de oito semestres letivos como padrão de referência para integralização curricular, porém com uma carga horária total menor, de 2.400 h./a. Além das tradicionais disciplinas, seminários e estágios curriculares, conforme as novas diretrizes curriculares do MEC para os três cursos, essa carga horária pode ser distribuída em diferentes tipos de atividades acadêmicas geradoras de créditos, tais como publicações, participações em eventos, discussões temáticas, atividades de iniciação à pesquisa, docência e extensão, vivência profissional complementar, dentre outros, mas todos sujeitos à avaliação do colegiado do curso.

Além dessas atividades, a estrutura dos novos currículos considera ainda as opções de formação complementar e formação livre, previstas no projeto de flexibilização curricular da UFMG, cujo objetivo é fazer com que - aluno seja co-responsável pela construção de seu currículo, conquistando assim não somente uma formação teórico-prática generalizada, mas também uma especialização em áreas de seu maior interesse. Ela prevê a possibilidade de que o aluno opte por fazer disciplinas de outros cursos de graduação oferecidos pela UFMG. A formação complementar, obrigatória para o currículo e opcional para o aluno, constitui-se por um conjunto de atividades acadêmicas que propiciam ao aluno a aquisição de conhecimentos, habilidades e atitudes em áreas de conhecimento conexas à de sua formação específica. Será oferecida na modalidade aberta, isto é, não haverá um elenco previsto de disciplinas a serem cursadas, sendo a escolha realizada pelo aluno, porém sob a orientação obrigatória e acompanhamento de um docente-tutor, aprovado pela colegiado de curso. 
O quadro de referência a partir do qual foram estruturadas as atividades é apresentado a seguir, na FIG. 1:

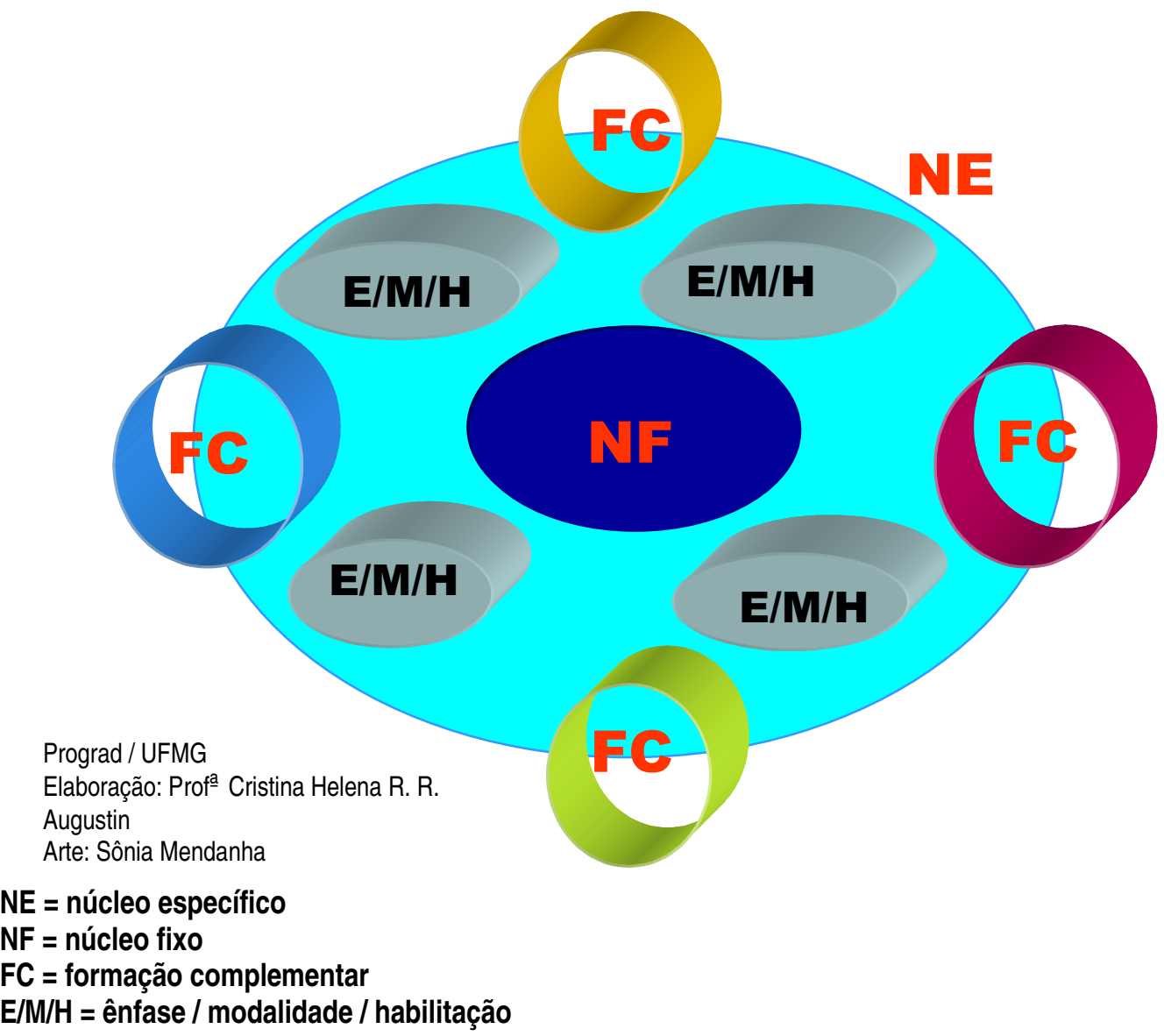

FIGURA 1 - Desenho esquemático da estrutura flexibilizada verticalmente $-2005$.

Os três cursos de graduação se estruturam a partir de um conjunto de atividades acadêmicas, perfazendo um total de $2.400 \mathrm{~h} / \mathrm{a}$, distribuídas do primeiro ao oitavo períodos. Dessas, 17 atividades (equivalentes a 960 $\mathrm{h} / \mathrm{a}$ ) constituem atividades acadêmicas do tronco comum da ciência da informação. O curso de Biblioteconomia e Gestão da Informação possui 14 atividades obrigatórias específicas do curso (equivalentes a $690 \mathrm{~h} / \mathrm{a}$ ) e 0 de Arquivologia, 10 atividades (total de $570 \mathrm{~h} / \mathrm{a}$ ). As horas restantes (510 h/a no curso de Biblioteconomia e Gestão da Informação, e 630 h/a no curso de Arquivologia) serão cumpridas dentre as atividades a serem escolhidas pelo aluno, como optativas, formação complementar, livre ou ainda outras atividades geradoras de crédito, citadas anteriormente.

Todas as atividades acadêmicas, com exceção da formação livre, contemplam os conteúdos vinculados às subáreas definidas como competências exigidas para a formação do profissional: Fundamentos Teóricos e Metodológicos da Ciência da Informação, Fundamentos de Tratamento e Organização da Informação, Usuários da Informação, Fundamentos Culturais, Políticos e Sociais da Informação, Fundamentos de Uso e Sistemas de Informação, Gestão da Informação, Tecnologia da 
Informação, acrescidos dos conteúdos das áreas de formação complementar ou livre.

As ementas de todas as disciplinas do tronco comum foram pensadas em termos de sua adequação tanto para o novo Curso de Biblioteconomia e Gestão da Informação quanto para os cursos de Arquivologia e Museologia. Dessa forma, o aluno de cada um dos cursos terá a oportunidade de estudar, debater e refletir tanto sobre aspectos gerais da ciência da informação como sobre aspectos específicos de seu curso e dos outros dois cursos que compõem a área. Deve-se destacar que elas estão distribuídas pelos oito semestres letivos dos três cursos, 0 que reflete a idéia do currículo proposto de não isolar, em momentos estanques, as disciplinas do tronco comum daquelas do tronco específico.

Optou-se por definir sua distribuição de forma gradativa pelo curso (em vez de concentrá-las, por exemplo, apenas no quinto e sexto períodos) de forma a não promover uma separação entre seus conteúdos e aqueles contemplados nas disciplinas do tronco comum.

As duas atividades de estágio curricular obrigatório, Estágio supervisionado em biblioteconomia e gestão da Informação I ou Estágio supervisionado em arquivologia I (70 período) e Estágio supervisionado em biblioteconomia e gestão da Informação II ou Estágio supervisionado em arquivologia II ( $8^{\circ}$ período). perfazem um total de 240 h./a.. A idéia é que, neste momento, os alunos consigam operar uma desejada síntese entre as questões teóricas e os fazeres práticos vistos ao longo do curso, conjugando-as na preparação e na implementação de um projeto em unidade de informação.

Para tanto, fazem parte ainda da estrutura do curso um amplo leque de disciplinas optativas, algumas voltadas para temáticas mais específicas das áreas de biblioteconomia, arquivologia, museologia e ciência da informação, além de outras formatadas como "tópicos", com conteúdo não previamente estabelecido, abrindo a possibilidade para a inclusão de novos temas, metodologias e técnicas que possam vir a surgir.

Deve-se destacar que o currículo dos três cursos prevê atividades acadêmicas de formação complementar em sete áreas do conhecimento: direito, administração e negócios, ciência da computação, ciências humanas (sociologia, história, comunicação social, filosofia, psicologia), preservação e conservação de bens culturais, artes e educação.

Já a formação livre é constituída pelo desenvolvimento, pelo aluno, de atividades acadêmicas que não fazem parte de sua formação específica ou complementar, com base em seus interesses individuais.

O colegiado do curso é que decidirá a quantidade de créditos a serem concedidos para atividades distintas, como participação em diversos tipos de congressos ou publicação em diversos tipos de periódicos.

A formação livre, complementar, disciplinas optativas e outras atividades geradoras de créditos devem perfazer o total de $510 \mathrm{~h}$./a. 


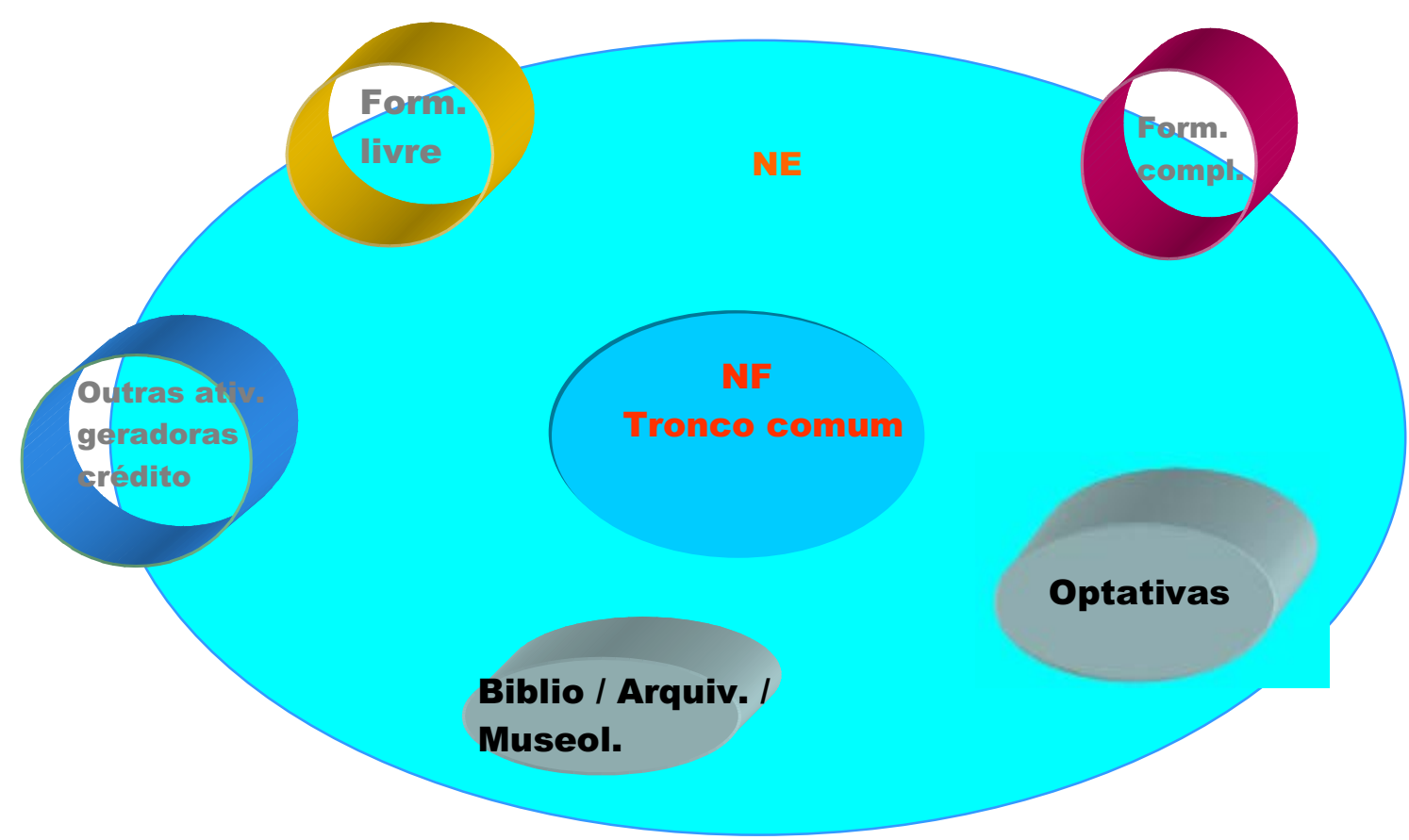

FIGURA 2 - Desenho esquemático da estrutura curricular dos cursos de Biblioteconomia e Gestão da Informação, Arquivologia e Museologia.

Fonte: Adaptado de AUGUSTIN, 2005.

\section{Proposta conceitual do curso de biblioteconomia e gestão da informação}

A profissão de bibliotecário foi uma das primeiras profissões regulamentadas no país e possui uma consolidada legislação, que a regulamenta. O Ministério do Trabalho e Emprego também relaciona na Classificação Brasileira de Ocupações - CBO 2002, disposta por áreas e atividades, os profissionais da informação sob o número 2612 e assim os identifica:

- BB - bibliotecário, nesta categoria o profissional pode trazer as denominações: bibliógrafo, biblioteconomista, cientista de informação, consultor de informação, especialista de informação, gerente de informação, gestor de informação;

- DC - documentalista;

- AI - analista de informações (analista de informação em rede).

Portanto, desde a Lei que rege a profissão até a tabela de classificação da CBO, notam-se visões ampliadas do profissional bibliotecário, às quais o presente projeto pedagógico visa se adequar.

A essência da adição da palavra gestão ao nome do curso está também diretamente vinculada às mudanças nos procedimentos e campos 
de atuação dos futuros profissionais. A convivência dos paradigmas dessas áreas faz referência ainda a este aspecto, pois se espera também, do bibliotecário, competência para atuação em outros contextos além da biblioteca (empresariais, comunitários, institucionais) e com outros suportes informacionais (além do tradicional livro e outras fontes de informação presentes nas bibliotecas). Tal necessidade se traduziu, então, pela complementação do nome do curso, com a incorporação da expressão "e gestão da informação". Essa incorporação traduz uma ampliação na esfera das habilidades e conteúdos formativos, sem prejuízo dos conteúdos teóricos e práticos que sustentam as atividades de bibliotecas e estão em consonância com a proposta de sua vinculação à ciência da informação.

Ao seguir a argumentação apresentada nas referências epistemológicas que fundamentam a criação dos cursos, pode-se identificar como objeto de estudo, em primeiro lugar, o conjunto de procedimentos técnicos - produção, coleta, organização, armazenagem, dentre outros - descritos por Borko (1968) como constituintes da ciência da informação, acrescidos da dimensão de otimização dos fluxos e processos de transferência da informação assinalados por Saracevic (1996).

Isso posto, verificou-se que as características necessárias ao curso apontavam para uma articulação dos cursos com outras áreas de conhecimento. O debate sobre a natureza interdisciplinar da ciência da informação vem se consolidando já há algumas décadas ( $p$. ex., GOMES, 2001; LOUREIRO; PINHEIRO, 1995; PAIM et al., 2001). Na ECI, ele está expresso nas formações diversificadas dos professores, mas, também, e principalmente, na atuação destes, nas parcerias efetivadas com diversas unidades acadêmicas e departamentos no âmbito da UFMG e mesmo fora dela.

Assim, previu-se a concretização desta articulação tanto a partir dessa competência instalada na Escola e da continuidade das atividades desenvolvidas como, também, na definição das disciplinas e outras atividades acadêmicas a compor os novos cursos (trazendo contribuições de áreas muito próximas como a administração, a ciência da computação, a comunicação social, a sociologia, dentre outras) e, principalmente, nas definições das formações complementares e da possibilidade de formações livres em outras áreas de conhecimento.

O profissional que se deseja formar no Curso de Biblioteconomias e Gestão da Informação de acordo com as discussões preliminares dos grupos de trabalho envolvidos com a reformulação curricular deverá:

ter domínio teórico e técnico dos processos de produção, seleção, registro, organização e disseminação da informação em diferentes suportes;

possuir habilidades de comunicação, de pesquisa, de gestão e de promoção de competência informacional do usuário;

conhecer os aspectos culturais, políticos e sociais relativos à informação e ao conhecimento. 
O conjunto dessas competências pode ser visualizado na FIG. 3, apresentada a seguir:

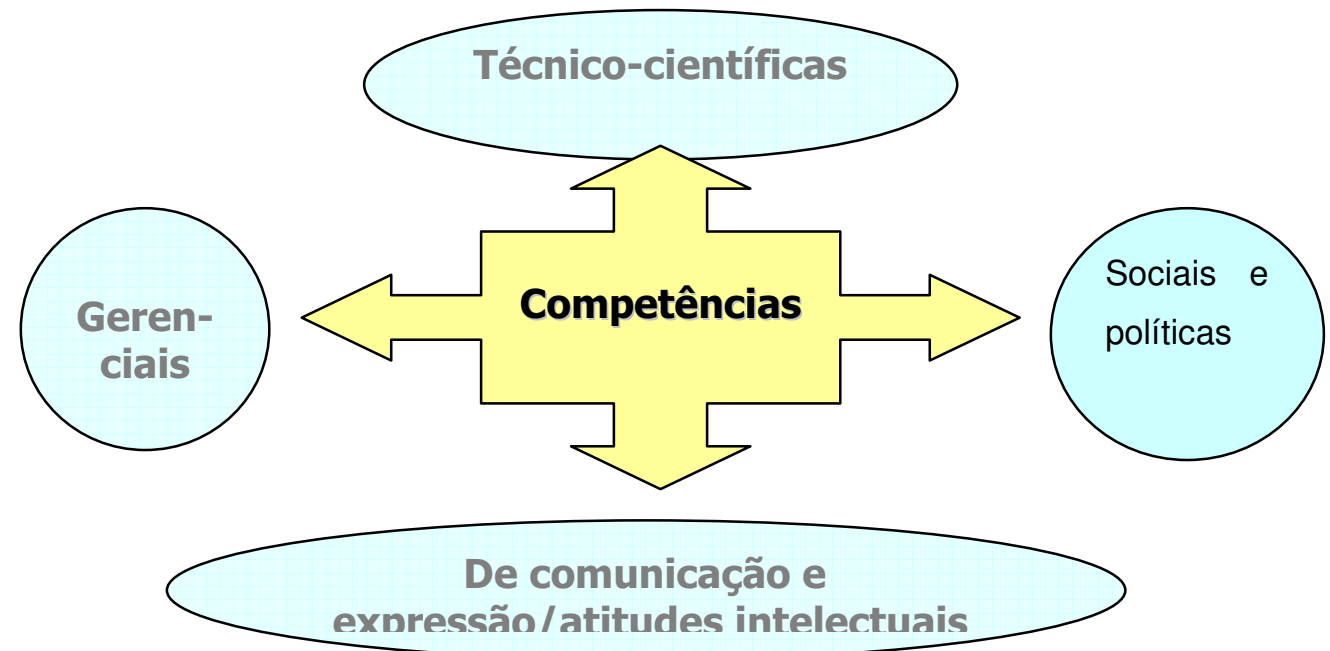

FIGURA 3 - Perfil e competências do profissional em Biblioteconomia e Gestão da Informação.

Fonte: BORGES et al, 2007.

Essas competências se desdobram em quatro grupos de competências mais específicas, relacionadas com as áreas de formação e os principais eixos constituintes do curso. São elas:

a) competências técnico-científicas:

entender o usuário (contextualizar, interpretar necessidades informacionais);

criar e selecionar informação (gerar, adquirir, analisar, sistematizar, avaliar);

organizar e prover acesso à informação (representar, sistematizar, recuperar, armazenar, preservar);

disseminar informação ( produtos e serviços).

b) Competências gerenciais:

elaborar políticas de informação para sistemas, serviços, unidades / instituições de informação;

administrar planos, projetos, equipes, sistemas, serviços, produtos em unidades / instituições de informação.

c) Competências sociais e políticas:

compreender e participar de contextos sociais e políticos;

participar, assessorar e intervir na formulação de políticas de informação em contextos específicos e governamentais;

atuar de forma coletiva com seus pares no âmbito das instituições sociais, com o objetivo da promoção e defesa da profissão e do meio social.

d) Competências formativas e atitudes intelectuais: 
desenvolver atitudes, relacionadas às conjunturas informacional e estrutural, de ética, de espírito investigativo; exercer liderança e promover a comunicação;

promover parcerias, auxiliar e tomar decisões e atuar de forma empreendedora.

A proposta de reformulação do Curso de Biblioteconomia para o Curso de Biblioteconomia e Gestão da Informação inserido numa perspectiva de criação de outros dois cursos de graduação na área de ciência da informação implica, desde sua origem, em adequações para o atendimento a essas especificações.

\section{Proposta conceitual do curso de ArquivologiA}

Além de terem domínio dos conteúdos da arquivologia os arquivistas devem estar preparados para enfrentar com proficiência e criatividade os problemas da sua prática profissional, particularmente as que demandam intervenções em arquivos, centros de documentação ou informação, centros culturais, serviços ou redes de informações, órgãos de gestão do patrimônio cultural.

São os arquivistas que projetam, implantam e mantêm organizado o sistema de gestão de documentos das organizações. Facilitar o fluxo de documentos, a armazenagem orgânica dos dossiês e o acesso e uso da memória institucional registrada em qualquer tipo de suporte são as principais tarefas do arquivista. O profissional pode ainda promover programas de treinamento de acesso a bases de dados, sempre buscando aprimorar o trabalho institucional.

A informática está cada vez mais presente como recurso para organizar as informações. Muitos arquivos estão se tornando verdadeiros bancos de dados virtuais, sendo acessados via Internet, o que agiliza o processo de busca e o registro das informações.

As diretrizes curriculares para a área, originadas do MEC, enumeram dentre as competências e habilidades dos graduados em arquivologia, as de caráter geral e comum, típicas desse nível de formação e aquelas de caráter específico.

Gerais:

- identificar as fronteiras que demarcam o respectivo campo de conhecimento;

- gerar produtos a partir dos conhecimentos adquiridos e divulgá-los;

- formular e executar políticas institucionais;

- elaborar, coordenar, executar e avaliar planos, programas e projetos;

- desenvolver e utilizar novas tecnologias;

- traduzir as necessidades de indivíduos, grupos e comunidades nas respectivas áreas de atuação; 
- desenvolver atividades autônomas, de modo a orientar, dirigir, assessorar, prestar consultoria, realizar perícias e emitir laudos técnicos e pareceres;

- responder a demandas de informação produzidas pelas transformações que caracterizam o mundo contemporâneo.

Específicas:

- compreender o estatuto probatório e informativo dos documentos de arquivo;

- identificar o contexto de produção de documentos no âmbito de instituições públicas e privadas;

- planejar e elaborar instrumentos de gestão de documentos de arquivo que permitam sua organização, avaliação e utilização;

- realizar operações relacionadas às funções arquivísticas: criação, classificação, avaliação, descrição, aquisição, preservação e difusão;

- compreender o arquivo como um sistema/rede de informação.

Alguns empregadores têm exigido ainda dos arquivistas, amplos conhecimentos gerais, iniciativa e um bom conhecimento de informática.

O Curso de Bacharelado em Arquivologia da ECI tem como fundamentação pedagógica $o$ oferecimento de disciplinas teóricas e práticas, obrigatórias e optativas, as opções de formação complementar e formação livre e também as atividades geradoras de créditos a serem avaliadas pelo colegiado do curso. (Ver grade curricular em anexo). Objetiva também abrir a possibilidade de expandir a visão dos alunos sobre as interações que a sua área de formação tem com outras profissões.

As atividades acadêmicas disponibilizadas pelo Curso de Arquivologia terão também como objetivo mostrar em que área os futuros profissionais poderão atuar e suas características próprias, assim como os recursos disponibilizados pelas novas tecnologias e sua utilização nas diversas áreas da profissão, sempre em atendimento aos interesses institucionais e dos usuários.

O fundamento básico do curso é, portanto, a formação humanística aliada ao fazer técnico. Essa conjugação implica a reflexão teórica e visa à formação de profissionais críticos capazes de atuar no mercado de trabalho atual.

Em relação às formações complementares, o Curso de Arquivologia prevê a oferta de seis áreas de formação complementar. São elas: direito, administração e negócios, computação, conservação e restauração de bens culturais móveis, história e biblioteconomia e gestão da informação. Além disso, o aluno pode optar por fazer outras atividades acadêmicas além das previstas, ou em outras áreas do conhecimento, na modalidade de formação complementar livre. 


\section{Considerações finais}

Espera-se com a reformulação do Curso de Biblioteconomia, juntamente com a introdução dos cursos de Arquivologia, acrescido do de Museologia, abranger as três áreas pertencentes ao grupo da ciência da informação. Essa proposta atende às normas da UFMG, que colocam como ponto básico em um projeto pedagógico a flexibilização curricular, que permite maior amplitude no escopo da formação de profissionais por parte da Escola de Ciência da Informação.

Contribuiu em primeira instância para o formato dos cursos propostos, o anseio de atualizar os conteúdos curriculares do Curso de Biblioteconomia e adequá-lo às novas tendências profissionais. $O$ novo Curso de Bacharelado em Biblioteconomia e Gestão da Informação tem sua identidade diretamente relacionada com os fatores que motivaram seu processo de reestruturação curricular, porém influenciada pela proposta de criação de outros dois cursos de graduação no âmbito da Escola de Ciência da Informação, Arquivologia e Museologia.

Torna-se ainda necessário destacar que serão institucionalizados procedimentos regulares de auto-avaliação dos cursos, por parte dos colegiados, do corpo docente e do corpo discente, incorporando os resultados no planejamento de ações de melhoria destes, principalmente na fase de implantação.

Tendo como parâmetros o perfil e as competências que se pretende atingir e as grades curriculares ora propostas, espera-se que os alunos da Escola de Ciência da Informação, tanto do Curso de Biblioteconomia e Gestão da Informação, quanto dos cursos a serem criados, em arquivologia e museologia, tenham a seu dispor um conjunto consistente de possibilidades de aprendizagem e de formação profissional, condizentes com as expectativas que se têm desses profissionais na sociedade da informação.

\section{Referências}

AUGUSTIN, C. H. R. R. Prograd/UFMG. Belo Horizonte, 2005. Inédito.

BARBOSA, R. R. et al. Novo nome e novo paradigma: da biblioteconomia à ciência da informação. Perspectivas em Ciência da Informação, Belo Horizonte, v. 5, n. especial, p. 81-91, jan./jun. 2000.

BORGES, M. E. N. et al. Reestruturação curricular do Curso de Graduação em Biblioteconomia da UFMG. In: ENCONTRO NACIONAL DE ENSINO E PESQUISA DA INFORMAÇÃO, Salvador, 2007. Anais do VII CINFORM Encontro ... Salvador: Instituto de Ciência da Informação da UFBA, 2007.

BORKO, $\mathrm{H}$. Information science: what is it? American Documentation, Chicago, v.19, n.1, p.3-5, Jan. 1968. 
GOMES, H. F. Interdisciplinaridade e ciência da informação: de característica a critério delineador de seu núcleo principal. Datagramazero, Rio de Janeiro, v. 2, n. 4, ago. 2001.

LOUREIRO, J. M.; PINHEIRO, L. V. Traçados e limites da Ciência da Informação. Ciência da Informação, Brasília, v. 24, n. 1, jan./abr. 1995. Disponível

em:

$<$ http://revista.ibict.br/index.php/ciinf/article/viewPDFInterstitial/531/483 >. Acesso em: 25 nov. 2008.

MIKSA, F. Library and information science: two paradigms. In: VAKKARI, P.; CRONIN, B. (Eds.). Conceptions of library and information science. Londres: T. Graham, 1992. p.229-252.

OTLET, P. Traité de documentation. Bruxelas: Mundaneum, 1934.

PAIM, I. et al. Interdisciplinaridade na ciência da informação: início de um diálogo. Perspectivas em Ciência da Informação, Belo Horizonte, v.6, n.1, p. 19- 26, jan./jun. 2001.

SARACEVIC, T. Ciência da informação: origem, evolução e relações. Perspectivas em Ciência da Informação, Belo Horizonte, v.1, n.1, p.41-63, jan./jun. 1996. 


\section{Anexo 1 - Grade curricular do Curso de Biblioteconomia e Gestão da Informação.}

\begin{tabular}{|c|c|c|c|c|c|}
\hline $\boldsymbol{1}$ & $\begin{array}{l}\text { Introdução à } \\
\text { biblioteconomia, } \\
\text { arquivologia e } \\
\text { museologia }\end{array}$ & $\begin{array}{l}\text { Fundamentos de } \\
\text { organização da } \\
\text { informação }\end{array}$ & $\begin{array}{l}\text { Informática aplicada } \\
\text { à ciência da } \\
\text { informação }\end{array}$ & Cultura e informação & $\begin{array}{l}\text { Teorias da } \\
\text { organização }\end{array}$ \\
\hline 2 & $\begin{array}{l}\text { Fundamentos da } \\
\text { ciência da } \\
\text { informação }\end{array}$ & $\begin{array}{l}\text { Gestão de unidades } \\
\text { de informação }\end{array}$ & $\begin{array}{l}\text { Introdução a bancos } \\
\text { de dados }\end{array}$ & Análise de assunto & $\begin{array}{l}\text { Elaboração e } \\
\text { apresentação do } \\
\text { trabalho científico }\end{array}$ \\
\hline 3 & $\begin{array}{l}\text { Linguagens de } \\
\text { indexação }\end{array}$ & $\begin{array}{l}\text { Métodos e técnicas } \\
\text { de pesquisa }\end{array}$ & $\begin{array}{l}\text { Usuários da } \\
\text { informação }\end{array}$ & $\begin{array}{l}\text { Catalogação } \\
\text { descritiva }\end{array}$ & $\begin{array}{l}\text { Introdução às fontes } \\
\text { de informação }\end{array}$ \\
\hline 4 & $\begin{array}{l}\text { Memória e } \\
\text { patrimônio cultural }\end{array}$ & $\begin{array}{l}\text { Planejamento em } \\
\text { unidades e sistemas } \\
\text { de informação }\end{array}$ & $\begin{array}{l}\text { Formação e } \\
\text { desenvolvimento do } \\
\text { acervo }\end{array}$ & $\begin{array}{l}\text { Acesso a fontes de } \\
\text { informação em meio } \\
\text { digital }\end{array}$ & $\begin{array}{l}\text { Sistemas de } \\
\text { recuperação da } \\
\text { informação }\end{array}$ \\
\hline \multirow[t]{3}{*}{5} & \multirow[t]{3}{*}{$\begin{array}{l}\text { Bibliotecas, arquivos } \\
\text { e museus digitais }\end{array}$} & $\begin{array}{l}\text { Preservação do } \\
\text { acervo (30H) }\end{array}$ & \multirow[t]{3}{*}{$\begin{array}{l}\text { Leitura e formação } \\
\text { do leitor }\end{array}$} & \multirow[t]{3}{*}{$\begin{array}{l}\text { Sistemas de } \\
\text { classificação: CDD }\end{array}$} & \multirow{2}{*}{$\begin{array}{l}\text { Pesquisa de } \\
\text { informação em meio } \\
\text { digital (30h) }\end{array}$} \\
\hline & & \multirow{2}{*}{$\begin{array}{l}\text { Competência } \\
\text { informacional } \\
(30 \mathrm{H})\end{array}$} & & & \\
\hline & & & & & $\begin{array}{l}\text { Outras atividades } \\
\text { acadêmicas } \\
(30 \mathrm{H})\end{array}$ \\
\hline 6 & $\begin{array}{l}\text { Sistemas de } \\
\text { classificação: CDU }\end{array}$ & $\begin{array}{l}\text { Organização } \\
\text { bibliográfica } \\
\text { nacional }\end{array}$ & $\begin{array}{l}\text { Serviços de } \\
\text { disseminação da } \\
\text { informação }\end{array}$ & $\begin{array}{l}\text { Outras atividades } \\
\text { acadêmicas }\end{array}$ & $\begin{array}{l}\text { Outras atividades } \\
\text { acadêmicas }\end{array}$ \\
\hline 7 & $\begin{array}{l}\text { Estágio curricular I } \\
(90 \mathrm{H})\end{array}$ & $\begin{array}{l}\text { Outras atividades } \\
\text { acadêmicas }\end{array}$ & $\begin{array}{l}\text { Outras atividades } \\
\text { acadêmicas }\end{array}$ & $\begin{array}{l}\text { Outras atividades } \\
\text { acadêmicas }\end{array}$ & $\begin{array}{l}\text { Outras atividades } \\
\text { acadêmicas } \\
(\mathbf{3 0 H})\end{array}$ \\
\hline 8 & $\begin{array}{l}\text { Estágio curricular II } \\
(150 \mathrm{H})\end{array}$ & $\begin{array}{l}\text { Outras atividades } \\
\text { acadêmicas }\end{array}$ & $\begin{array}{l}\text { Outras atividades } \\
\text { acadêmicas } \\
(30 \mathrm{H})\end{array}$ & $\begin{array}{l}\text { Outras atividades } \\
\text { acadêmicas } \\
(30 \mathrm{H})\end{array}$ & $\begin{array}{l}\text { Outras atividades } \\
\text { acadêmicas } \\
(30 \mathrm{H})\end{array}$ \\
\hline
\end{tabular}

Obs: fundo amarelo, tronco comum; fundo lilás, tronco especifico de Biblioteconomia e Gestão da Informação; fundo cinza, atividades acadêmicas de flexibilização curricular. Todas as atividades acadêmicas possuem $60 \mathrm{~h} / a u l a$, com exceção das atividades assinaladas. 
Beatriz Valadares Cendón; Carlos Alberto Ávila Araújo; Cíntia de Azevedo Lourenço; Lídia Alvarenga; Lígia Maria Moreira Dumont; Marlene de Oliveira; Mônica Erichsen

Nassif; Renato Rocha Souza

\section{Anexo 2 - Grade curricular do Curso de Arquivologia}

\begin{tabular}{|c|c|c|c|c|c|}
\hline 1 & $\begin{array}{l}\text { Introdução à } \\
\text { biblioteconomia, } \\
\text { arquivologia e } \\
\text { museologia }\end{array}$ & $\begin{array}{l}\text { Fundamentos de } \\
\text { organização da } \\
\text { informação }\end{array}$ & $\begin{array}{l}\text { Informática aplicada } \\
\text { à Ciência da } \\
\text { Informação }\end{array}$ & Cultura e informação & $\begin{array}{l}\text { Teorias da } \\
\text { organização }\end{array}$ \\
\hline 2 & $\begin{array}{l}\text { Fundamentos da } \\
\text { ciência da informação }\end{array}$ & $\begin{array}{l}\text { Gestão de unidades } \\
\text { de informação }\end{array}$ & $\begin{array}{l}\text { Introdução aos } \\
\text { bancos de dados }\end{array}$ & Análise de assunto & $\begin{array}{l}\text { Fundamentos de } \\
\text { arquivologia }\end{array}$ \\
\hline 3 & $\begin{array}{l}\text { Linguagens de } \\
\text { indexação }\end{array}$ & $\begin{array}{l}\text { Métodos e técnicas de } \\
\text { pesquisa }\end{array}$ & $\begin{array}{l}\text { Usuários da } \\
\text { informação }\end{array}$ & $\begin{array}{l}\text { Organização e } \\
\text { métodos aplicados à } \\
\text { arquivologia }\end{array}$ & $\begin{array}{l}\text { Gestão de } \\
\text { documentos } \\
\text { arquivísticos }\end{array}$ \\
\hline 4 & $\begin{array}{l}\text { Memória e } \\
\text { patrimônio cultural }\end{array}$ & $\begin{array}{l}\text { Planejamento em } \\
\text { unidades e sistemas } \\
\text { de informação }\end{array}$ & $\begin{array}{l}\text { Descrição de } \\
\text { documentos } \\
\text { arquivísticos }\end{array}$ & $\begin{array}{l}\text { Avaliação de } \\
\text { documentos } \\
\text { arquivísticos }\end{array}$ & $\begin{array}{l}\text { Outras atividades } \\
\text { acadêmicas }\end{array}$ \\
\hline 5 & $\begin{array}{l}\text { Bibliotecas, arquivos } \\
\text { e museus digitais }\end{array}$ & $\begin{array}{l}\text { Preservação do } \\
\text { acervo (30H) }\end{array}$ & \multirow{2}{*}{$\begin{array}{l}\text { Gestão arquivística } \\
\text { de documentos } \\
\text { eletrônicos }\end{array}$} & \multirow[t]{2}{*}{$\begin{array}{l}\text { Arquivos } \\
\text { permanentes }\end{array}$} & \multirow[t]{2}{*}{$\begin{array}{l}\text { Outras atividades } \\
\text { acadêmicas }\end{array}$} \\
\hline & & $\begin{array}{l}\text { Competência } \\
\text { informacional }(30 \mathrm{H})\end{array}$ & & & \\
\hline \multirow[t]{2}{*}{6} & \multirow[t]{2}{*}{$\begin{array}{l}\text { História } \\
\text { administrativa do } \\
\text { Brasil e regional }\end{array}$} & \multirow[t]{2}{*}{$\begin{array}{l}\text { Planejamento e } \\
\text { gestão de redes e } \\
\text { sistemas de arquivos }\end{array}$} & $\begin{array}{l}\text { Diplomática e } \\
\text { tipologia documental } \\
(30 \mathrm{H})\end{array}$ & \multirow[t]{2}{*}{$\begin{array}{l}\text { Outras atividades } \\
\text { acadêmicas }\end{array}$} & \multirow[t]{2}{*}{$\begin{array}{l}\text { Outras atividades } \\
\text { acadêmicas }\end{array}$} \\
\hline & & & $\begin{array}{l}\text { Outras atividades } \\
\text { acadêmicas }(30 \mathrm{H})\end{array}$ & & \\
\hline 7 & $\begin{array}{l}\text { Estágio curricular I } \\
(90 \mathrm{H})\end{array}$ & $\begin{array}{l}\text { Outras atividades } \\
\text { acadêmicas }\end{array}$ & $\begin{array}{l}\text { Outras atividades } \\
\text { acadêmicas }\end{array}$ & $\begin{array}{l}\text { Outras atividades } \\
\text { acadêmicas }\end{array}$ & $\begin{array}{l}\text { Outras atividades } \\
\text { acadêmicas } \\
(30 \mathrm{H})\end{array}$ \\
\hline 8 & $\begin{array}{l}\text { Estágio curricular II } \\
(150 \mathrm{H})\end{array}$ & $\begin{array}{l}\text { Outras atividades } \\
\text { acadêmicas }\end{array}$ & $\begin{array}{l}\text { Outras atividades } \\
\text { acadêmicas } \\
(30 \mathrm{H})\end{array}$ & $\begin{array}{l}\text { Outras atividades } \\
\text { acadêmicas } \\
(30 \mathrm{H})\end{array}$ & $\begin{array}{l}\text { Outras atividades } \\
\text { acadêmicas } \\
(30 \mathrm{H})\end{array}$ \\
\hline
\end{tabular}

Obs: fundo amarelo, tronco comum; fundo laranja, tronco especifico de Arquivologia; fundo cinza, atividades acadêmicas de flexibilização curricular. Todas as atividades acadêmicas possuem 60 h/aula, com exceção das atividades assinaladas. 